\title{
Cluster of travel-associated Legionnaires' disease in Lazise, Italy, July to August 2011
}

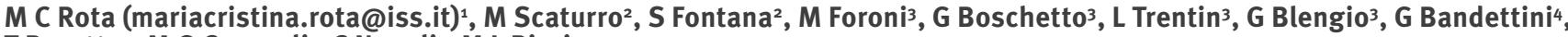
T Buratto ${ }^{4}$, M G Caporali ${ }^{1}$, C Napoli ${ }^{1}$, M L Ricci ${ }^{2}$

1. National Centre for Epidemiology, Surveillance and Health Promotion, Istituto Superiore di Sanità, Rome, Italy

2. Department of Infectious, Parasitic and Immune-mediated Diseases, Istituto Superiore di Sanità, Rome, Italy

3. Service of Hygiene and Public Health, ULSS 22 Bussolengo, Italy

4. Regional Reference Laboratory for Legionella, Padua, Italy

Rota MC, Scaturro M, Fontana S, Foroni M, Boschetto G, Trentin L, Blengio G, Bandettini G, Buratto T, Caporali MG, Napoli C, Ricci ML. Cluster of travel-associated Legionnaires' disease in Lazise, Italy, July to August 2011

Euro Surveill. 2011;16(40):pii=19982. Available online: http://www.eurosurveillance.org/ViewArticle.aspx?Articleld=19982

Article published on 6 October 2011

Since 18 August 2011, 17 cases of travel-associated Legionnaires' disease have been reported. They were tourists from five European countries who had stayed in five accommodation sites in Lazise, Italy. The dates of symptom onset ranged from 18 July to 25 August 2011. Control measures were implemented and no further cases associated with stays at the sites have been reported after disinfection. Timely notification of any further cases potentially associated with stay in Lazise is recommended.

\section{Cluster description}

A total of 17 cases of travel-associated Legionnaires' disease have been reported since 18 August 2011 that were associated with a stay in several accommodation sites in Lazise, Italy. All cases - seven from the Netherlands, six from Germany, two from Italy, one from Austria and one from Denmark - stayed at five different accommodation sites (two campsites and three hotels) in Lazise between the beginning of July and end of August 2011. Dates of symptom onset ranged from 18 July 2011 to 25 August 2001 (Figure). The ages of the cases ranged from 42 to 78 years (mean: 57; standard deviation: 11.9$)$ and the male to female ratio was 3.3 to 1 .

\begin{abstract}
Background
Legionnaires' disease is a lung infection caused by Legionella bacteria. The bacteria live in water or wet soil and must be inhaled to cause infection. Legionella can cause a severe form of pneumonia (Legionnaires' disease), which in Europe can be fatal for about 5-15\% of people with the disease, but it can also cause a mild influenza-like infection without pneumonia, called Pontiac fever [1].
\end{abstract}

Over the last 10 years, the number of cases of Legionnaires' disease in Italy has been steadily increasing, from 325 cases in 2001 to 1,200 cases in 2009 , with an incidence in 2009 of 2 per 100,000 population $[2,3]$. The number of cases of travel-associated Legionnaires' disease has also been increasing: every year, several clusters associated with accommodation sites, involving tourists from Italy and elsewhere in Europe, are reported $[4,6]$. Most of this increase has been attributed to improved diagnostic tools, in particular the urinary antigen detection test [7].

The European Legionnaires' Disease Surveillance Network (ELDSNet), coordinated by the European Centre for Disease Prevention and Control (ECDC) since

\section{FIgURE}

Cases of travel-associated Legionnaires' disease by date of symptom onset and nationality, Lazise, Italy, notified by ELDSNet as of 21 September $2011(n=17)$

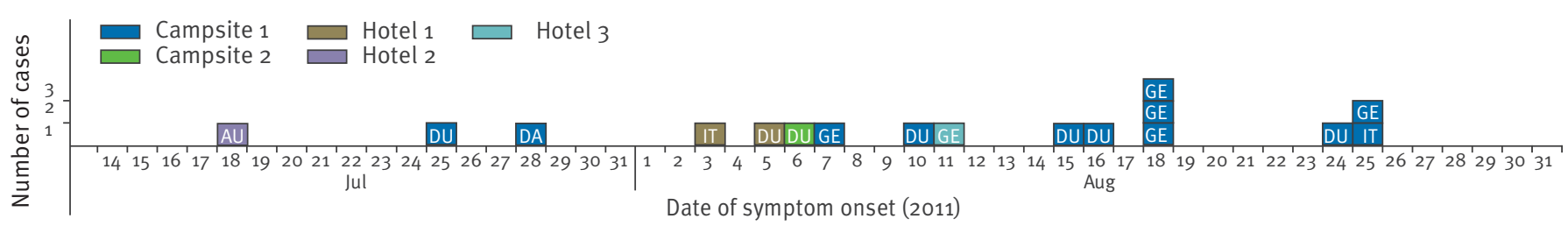

AU: Austrian; DA: Danish; DU: Dutch; GE: German; IT: Italian.

ELDSNet: European Legionnaires’ Disease Surveillance Network. 
April 2010, carries out surveillance of Legionnaires' disease, involving all European Union Member States, Iceland and Norway. It aims to identify relevant public health risks, enhance disease prevention and monitor epidemiological trends. In this context, surveillance of travel-associated disease is carried out on a day-today basis to inform urgent public health action, with the aim of preventing subsequent cases. Each travelassociated case of Legionnaires' disease diagnosed in a participating European country is reported by national ELDSNet collaborators to ELDSNet as quickly as possible. If other cases are found to have been associated with a particular accommodation site within a two-year period, a cluster is identified. A rapid risk assessment of the accommodation site associated with the cluster is undertaken by the country in which the site is located: the results are reported to ECDC and shared with all countries in the network $[8,9]$.

\section{Testing isolates and data collection}

Of the 17 reported cases reported in Lazise, 16 were confirmed by a urinary antigen test and one case remained probable because diagnosis was on the basis of a single high Legionella-specific antibody titre. Legionella pneumophila serogroup 1 was isolated from two patients: one had stayed at Campsite 1 and one at Campsite 2. There were no deaths.

Lazise is a small town located about $20 \mathrm{~km}$ northwest of Verona, by Lake Garda (the largest lake in the country). It has 7,000 inhabitants and there are an estimated 60,000 visitors during the summer holiday period. Legionnaires' disease was not reported in Lazise inhabitants in July and August 2011. The disease has been reported in tourists staying in neighbouring villages in the Lake Garda area, as expected based on the previous years' notifications (unpublished data).

Patients were contacted by ELDSNet national collaborators in their country of residence. Information about potential exposure in the 10 days preceding the onset of symptoms (incubation period for Legionnaires' disease is 2-10 days) was obtained using a standardised questionnaire: national ELDSNet collaborators of the countries where cases were reported recorded the details in an ad hoc restricted-access web-based database set up by ELDSNet. Analysis of the data revealed common accommodation sites but no other common exposure.

\section{Ongoing investigations}

Epidemiological and environmental investigations, which started immediately after notification of the cluster by ELDSNet on 19 August 2011, are ongoing. The Istituto Superiore di Sanità is supporting the local health authorities in Lazise.

Of the 17 reported cases, 12 had stayed in Campsite 1 (accommodating about 3,500 people), two had stayed in Hotel 1 (with about 40 rooms), two in two different hotels (Hotels 2 and 3 with about 50 rooms each) and one in Campsite 2 (accommodating about 1,800 people).

Three of the five accommodations sites (Campsite1, Campsite 2 and Hotel 1) were found to be within approximately 500 metres of each other. The water sources for the five accommodation sites are different: the two campsites are supplied by private wells while the three hotels are supplied by the same public service. Local rapid risk assessment was promptly carried out [10] and several water samples were collected for testing by the regional and the national reference laboratories according to procedures indicated for the control and prevention of legionellosis [11]. In the first round of sampling, 56 samples of cold and hot water were collected from water tanks, taps, shower heads, swimming pools, water sprinklers, decorative fountains and jacuzzis at the five accommodation sites. Two samples from Campsite 1 were found positive for L. pneumophila serogroup 1 , with a concentration of 900 and 4,100 colony forming units per liter (CFU/L). These two samples had been collected from distal water outlets in one of the seven washing and toilet facilities. In Hotel 2, three samples were found positive for L. pneumophila serogroup 1, at concentrations ranging from 2,000 to $12,000 \mathrm{CFU} / \mathrm{L}$. L. pneumophila serogroup 2-14 was isolated from other water points in all five accommodation sites.

No cooling towers were found in Lazise and its outskirts. To date, no installations have been identified as a potential source of Legionella.

\section{Typing of Legionella isolates}

The two L. pneumophila serogroup 1 clinical isolates were characterised by sequence-based typing [12]: both were sequence type (ST) 23 , as were the two L. pneumophila serogroup 1 isolates from the environmental samples. Further molecular investigations are ongoing.

\section{Control measures}

A rapid risk assessment conducted promptly in all five accommodation sites allowed us to implement control measures. Disinfection of the water systems in all five accommodation sites involved was carried out as a control measure and all devices generating aerosols (e.g. spa pools, lawn sprinklers and decorative fountains) were immediately deactivated. Hospitals and general practitioners (GPs) in the area were alerted in order to enhance clinical surveillance of the disease. People staying at Campsite 1 (which reported the greatest number of cases) and for whom email addresses were available were informed by email of the ongoing cluster of the disease and were encouraged to contact their GPs if they developed symptoms. Managers of all the accommodation sites, spas and other recreational sites in the municipality were also informed through a note issued by the Mayor of Lazise and were made aware of the importance of adopting adequate measures to prevent legionellosis. 
Environmental sampling, repeated after disinfection of the water systems, was negative for Legionella and no further cases have been notified after the risk management measures were adopted.

\section{Conclusion}

As a common source of infection in Lazise has not yet been identified, there may be an ongoing risk of exposure to Legionella for persons visiting or residing in the town. For this reason, we encourage timely notification of further cases potentially associated with stay in Lazise.

\section{References}

1. European Centre for Disease Prevention and Control (ECDC) Legionellosis. Stockholm: ECDC. [Accessed 5 Oct 2011]. Available from:http://ecdc.europa.eu/en/healthtopics/ legionnaires disease/Pages/index.aspx

2. Rota MC, Castellani Pastoris M, Salmaso S. Rapporto annuale sulla legionellosi in Italia nel 2001 [Legionellosis in Italy: 2001 annual report]. Notiziario ISS. 2002;15:11-5. Italian. Available from: http://www.iss.it/binary/publ/publi/0210.1107342628. pdf

3. Rota MC, Caporali MG, Giannitelli S, Mandarino G, Scaturro M, Ricci ML. Rapporto annuale sulla legionellosi in Italia nel 2009 [ Legionellosis in Italy: 2009 annual report]. Notiziario ISS. 2010;23:3-9. Italian. Available from: http://www.iss.it/binary/ publ/cont/onlineo9.pdf

4. Ricketts KD, Yadav R, Rota MC, Joseph CA; European Working Group for Legionella Infections. Characteristics of reoffending accommodation sites in Europe with clusters of Legionnaires' disease, 2003-2007. Euro Surveill. 2010;15(40):pii=19680. Available from: http://www.eurosurveillance.org/ViewArticle. aspx?Articleld $=19680$

5. Rota MC, Cano Portero R, Che D, Caporali MG, Hernando $\mathrm{V}$, Campese C. Clusters of travel-associated Legionnaires' disease in Italy, Spain and France, July 2002 - June 2006. Euro Surveill. 2007;12(11): pii=744. Available from: http://www. eurosurveillance.org/ViewArticle.aspx?Articleld=744

6. Joseph CA, Ricketts KD, Yadav R, Patel S; European Working Group for Legionella Infections. Travel-associated Legionnaires disease in Europe in 2009. Euro Surveill. 2010; 15(41): pii=19683. Available from: http://www.eurosurveillance. org/ViewArticle.aspx?Articleld=19683

7. Campese C, Bitar D, Jarraud S, Maine C, Forey F, Etienne J, et al. Progress in the surveillance and control of Legionella infection in France, 1998-2008. Int J Infect Dis. 2011; 15(1): e30-7.

8. Decision No 2119/98/EC of the European Parliament and of the Council of 24 September 1998 setting up a network for the epidemiological surveillance and control of communicable diseases in the Community. Official Journal of the European Union. Luxembourg: Publications Office of the European Union. 03.10.1998:L 268. Available from: http://eur-lex.europa.eu/ LexUriServ/LexUriServ.do?uri=CELEX:31998D2119:EN:HTML

9. European Centre for Disease Prevention and Control (ECDC). European Legionnaires' Disease Surveillance Network (ELDSNet). Stockholm: ECDC. [Accessed 30 Sep 2011]. Available from: http://www.ecdc.europa.eu/en/activities/surveillance/ eldsnet/pages/index.aspx

10. European Centre for Disease Prevention and Control (ECDC). Outbreak of Legionnaires' disease in Lazise, Italy, July August 2011. Rapid risk assessment. September 2011. Stockholm: ECDC; 2011. Available from :http://ecdc.europa.eu/en/ publications/Publications/2011_09_TER_legionnaire_italy.pdf

11. Documento di linee-guida per la prevenzione e il controllo della legionellosi [Guidelines for legionellosis prevention and control]. Gazzetta Ufficiale della Repubblica Italiana No. 103. 5 May 2000. Italian. Available from: http://www.iss.it/binary/ iss3/cont/05_05_00.1144152817.pdf

12. European Working Group for Legionella Infections. Sequencebased typing (SBT) protocol for epidemiological typing of Legionella pneumophila. Version 4.2. 9 Oct 2009. Available at: http://www.hpa-bioinformatics.org.uk/legionella/legionella $\mathrm{sbt} / \mathrm{php} / \mathrm{SBT} \% 2$ oprotocol\%20for\%20website $\% 202008 \% 20$ v4.2.pdf 